\title{
PSYCHIATRIC INDICATIONS FOR THE TERMINATION OF PREGNANCY
}

\author{
By E. W. Anderson, M.D., F.R.C.P., D.P.M. \\ Professor of Psychiatry, University of Manchester, and Director, Department of Psychiatry, \\ Manchester Royal Infirmary
}

In general medicine the indications for therapeutic abortion are more or less tangible, although over the last few decades reduced in number. In psychiatry matters are otherwise. Psychiatric diagnosis in the strict sense (i.e. excluding those illnesses where a brain pathology exists) rests on purely psychological criteria, the interpretation of which sometimes varies from one observer to another. This is particularly true in certain atypical psychoses. Yet, as we shall see, a correct diagnosis in these cases may be of particular importance when the question of therapeutic abortion arises. Our ignorance of this problem (which might well be in large part of our own making) is very great. The reasons for this are easy to find. Factual data are few. The number of cases referred for an opinion on the advisability of termination of pregnancy on psychiatric grounds is necessarily relatively small, although wide variations in the figures are found.

Few attempts have been made to study the indications closely and katamnestic studies have not been made until comparatively lately, although the necessity for these has been urged for many years. Hence the vast bulk of the literature on this subject reflects opinions or impressions derived from imperfectly studied and recorded cases. These opinions, moreover, are often influenced by a number of distorting factors: the writer's particular psychiatric school, his own religious or ethical views and the particular legislation of his country. It may be said that the literature on the subject falls into two parts: that of clinical impressions and that based on more systematic observation and study. The latter work, carried out notably in Switzerland and Sweden, has been assisted by recent legislative changes in these countries. Nevertheless, sharp differences of opinion persist. Even at the present day it is difficult to disagree with Boyd when he says ' there is little evidence proving that induced abortion has a therapeutic value in arresting the development of a mental disorder in predisposed individuals or those already suffering from mild mental disturbances.' Nevertheless, psychiatric indications for the therapeutic termination of pregnancy are accepted by reputable authority. Whilst in general medicine therapeutic abortion is largely-not entirely-a purely ' medical ' matter, in psychiatric practice many other considerations arise which are apt to dilute or contaminate the purely medical approach. Abortion touches the very quick of a woman's life and arouses a host of powerful and conflicting emotional attitudes both in the patient and in her family, of which it is the explicit duty of the psychiatrist to take account. Apart from the still insecure legal status of the practitioner in the matter, the procedure itself, it must be remembered, is not devoid of potential danger to the patient, even in skilled hands. Therapeutic abortion is only implicitly, not explicitly, recognized in English law, certainly as far as clause $5^{8}$ of the Offences Against the Person Act, 186r, is concerned, although this statement might require qualification in the light of a provision of the Infant Life (Preservation) Act, I929, which sanctions abortion if done in good faith to save the life of the mother. In the former Act the operative word is ' unlawfully,' i.e. intentionally ' without just cause or excuse.' If the practitioner's motives and intentions are above suspicion and he acts from the dictates of his conscience, he has not much to fear (Humphreys). Discussion has centred on the question of safeguarding the mother's health as well as her life. Riddell states 'there is no doubt that a miscarriage may be lawfully procured not only to save the mother's life, but to avoid serious injury to her health,' and quotes 'Russell on Crimes' in support. Nor need the damage to health be permanent; it must, however, be serious and, he adds, " a woman who becomes pregnant must be prepared to undergo the ordinary discomforts of pregnancy and to take the ordinary risks.' In the well-known Bourne çase the learned judge ruled that 'preserving the life of the woman' should not necessarily be construed as 'preserving 
the woman from death'. But, as Sydney Smith and Hobson (who has discussed this case at some length) remind us, such a ruling is not necessarily binding for the future. In an effort to clarify and safeguard the doctor's position, Lord Amulree* in 1954 introduced a Bill into the Lords designed to this end, but nothing came of this. More recently (1955) $\dagger$ the Council of the Magistrates' Association approved a resolution (with, however, a large dissenting minority) recommending that no doctor could be found guilty unless it were proved that the operation had not been performed in good faith to save the mother's life or prevent serious injury to her. Summaries of comparative law on abortion have been made by Taussig, Balmer and Klintskog.

As regards the religious aspects, the teaching of the Roman Catholic Church (restated in the Papal Encyclical of 1930, 'Casti Conubii') is alone important. The Roman Catholic view has been discussed by several medical writers, Taussig and Meinertz and by psychiatrists, notably Strub and H. Schneider, who comment on the Church's differentiation of ' direct' and 'indirect' killing of the foetus (i.e. occurring as an unwilled act in necessary treatment of the mother for a grave medical condition). Hopes raised in some quarters by this concession that the Church might sometimes recognize the medical indication for termination have remained unfulfilled.

The indications for therapeutic abortion are four -medical, social, humanitarian and eugenic. Some or all of these are recognized in some other countries. Apart from the medical, the most important, as it is the most pervasive and obtrusive, is the social, which has received much attention in the literature. It is impossible, as H. W. Maier and Peller, and also Hart, have particularly emphasized, to dissociate entirely the social from the medical aspects, particularly in psychiatric illness, because of their etiological significance. The new Swedish law attempted to exclude the social indication, but in face of the liberal character of these laws was compelled to capitulate to some extent by admitting it in disguised form as a 'social-medical' and 'medical-social' indication (Ekblad, Simson). Clearly this gives an enormously wide latitude to the doctor, who has thus thrust upon him a task outside his competence. If the social indication is admitted, assessment of social need must lie in other than medical hands. Some of the dangers of this were pointed out many years ago by the late Lord Justice Salter and by many other writers. The establishment of an official body for the purpose has been discussed by some, but such a body is

* Manchester Guardian, January 28, 1954.

$\dagger$ The Times, October 22, 1955. unlikely to be tolerable in this country and, as Glaus has remarked, it would defeat its end. If, however, the social indication cannot be admitted, then the duty devolves on the State to provide the utmost social support for the needy or distressed mother, whether married or unmarried. This should be a first priority, since the misery caused by illegal abortion is enormous, as Teare has recently and arrestingly shown.

The humanitarian indication found its most vigorous champion in $\mathrm{H}$. W. Maier, who held strongly that pregnancy should be terminated in cases of criminal assault, especially in very young girls, because of the adverse effects of the experience. McIlroy, E. Meyer and James have spoken similarly. The objections raised are: First, that it would be very difficult to eliminate fraud, not necessarily entirely conscious, and Maier's recommendation that the doctor alone should be entrusted with the decision is unacceptable. No doubt the problem might be solved by setting up a panel consisting of both doctors and lawyers, but the same objections apply here as to any official body intervening in a matter of this kind. Secondly, it is by no means proven that pregnancy in very young girls has such harmful effects as Maier supposes. Studies by Fairfield and by myself do not support his view. In Sweden this indication is legally recognized, but has arisen onlo of exceptionally (37 cases in the years 1939-43. Ekblad). The eugenic indication is perhaps the most doubtful of them all. Psychiatric genetics, despite its advances, cannot offer more than a statistical prognosis, and as long as this is so it would seem undesirable on this alone, as also upon several other grounds, to recognize it legally.

The incidence of therapeutic abortion on psychiatric grounds varies widely. Heffernan and Lynch, from 152 adequate replies to a questionnaire directed to a number of American hospitals, found, for the Io-year period I94I-50, 2,7I 7 therapeutic abortions for all causes out of $1,135,618$ deliveries (2.38 per cent.), of which 377 were psychiatric, nearly I4 per cent. of the total number 8 of abortions. Figures from the Children's Hospital, San Francisco (five-year period), were $3^{8}$ per cent. for psychiatric reasons (Stephenson), a figure just exceeded by University College Hospital, London, 을 with 38.9 per cent. (Nixon). Balmer found nearly 20 per cent. for psychiatric reasons in the figures $\Omega$ for 1942 for Canton Berne. In 2,350 abortions $N$ reported by Davis there was none for psychiatric $\mathbb{W}^{-}$ reasons. It is clear that opinione on psychiatric 'indications' vary very widely indeed and the figures speak for themselves.

Psychiatric Indications

Only a few representative views will be given. 
R. H. Cole (1927) believed that a woman with strongly positive heredity for mental illness or who had had a puerperal psychosis should be advised against pregnancy, but if pregnant should go to term. Even where exhaustion symptoms were present he doubted the efficacy of abortion. In certain obsessional states termination might be advisable. Suicidal threats called for supervision. Hart (1929) advised similarly. Abortion was unlikely to affect favourably the course of either manic-depressive illness or schizophrenia, nor even of toxic-infective psychoses. In the psychoneuroses, however, "there was no place for rigid principles or opinions,' but where pregnancy formed a focus of deeply-rooted anxieties abortion was justifiable, but it was a question of degree. The Royal Medico-Psychological Association in 1927 stated that 'the weight of evidence was against the growing practice of inducing abortion for the prevention of mental disorders ...' (Lord). The majority of 95 British psychiatrists circularized by Robinson (1933) disapproved therapeutic abortion on psychiatric grounds, although it might occasionally be justified, but the indications were imprecise. Pearce (1957) similarly circularized 45 psychiatrists and one general practitioner and found agreement ' largely lacking.' Bumke (1936), associating himself with the leading psychiatrists of Germany, held that psychiatric indications for abortion very rarely arose. On the other hand, Eden and Brill adopted an extremely liberal attitude to say the least.

Termination in schizophrenia is a more controversial matter. German-speaking authorities (Kogerer, Ewald, E. Meyer, H. W. Maier, Binder, Leferenz), basing their views on the assumption that schizophrenia is a 'process' disease, believe that in certain cases of schizophrenia pregnancy acts unfavourably. Binder holds that termination is only justified when a schizophrenic illness appears for the first time at the beginning of a pregnancy or when previous pregnancies have adversely affected such an illness. Some recent American writers (Wilson, Kummer, Ebaugh and Heuser) also recommend termination in certain cases of schizophrenia, as also did some of Pearce's correspondents. It is here that the diagnosis of the atypical psychosis already mentioned is important. It remains to consider the newer work from Switzerland and Sweden. This is important, since for the first time an attempt has been made at systematic study of the problem. Binder in Zürich found from his study of $35^{\circ}$ unmarried mothers that 7 per cent. developed a state of chronic mental invalidism because of the enduring stress of the situation, but 128 women of normal constitution, whatever the stress, remained fit. Further impetus was given to these studies by changes in the Swiss
Federal Law of 1942, which allowed termination where lasting severe damage to the mother's health could be predicted from the pregnancy. Binder lays down two essential criteria: (I) existence of abnormal psychic constitution before the pregnancy and (2) exceptional severity of the situation resulting from pregnancy. Both must be present to justify abortion. This is certainly an important contribution, but it is doubtful whether in practice. it takes us much further. Binder's study was made on patients he had not personally examined. Whilst his findings may have general significance, they do not always help in assessing the individual case; they relate, moreover, to a population which probably differs a good deal from our own and, lastly, the doctor is thrown back on the social factor to some extent.

Ekblad, in Stockholm, followed up 479 women who had been legally aborted under the new laws. Sixty-five per cent. of the women showed no adverse effects, ro per cent. found the operation unpleasant, I4 per cent. showed mild and I I per cent. serious self-reproach. There was a greater risk of this if the women had been over-persuaded to submit to the operation. No other factors emerged as prognostic pointers to this development, but the stronger the psychiatric indication, the greater the risk. Siegfried found such depressive reactions in 59 per cent. in a series of $6 r$. Polonio and Figueiredo found abortion responsible for 20 per cent. of a series of 244 cases of puerperal psychoses. They believe that pregnancy has a protective rather than a traumatic effect; Vallejo Nagera found only 2 per cent. such illnesses attributable to abortion. In my own study of now nearly 60 cases (briefly reported elsewhere) only four depressive reactions followed abortion.

Estimation of suicidal risk varies. Binder found attempts in 5 per cent., preoccupation in 17 per cent. of his series. In my own series of 52 women suicidal risk of some degree occurred in 23. Yet in a series of nearly 70 adolescent unmarried mothers studied in the University of Manchester Psychiatric Department (not yet published) in none, which agrees with Binder's view that suicide in pregnancy is relatively uncommon.

Follow-up studies of women refused abortion (Amstad, Neuweiler, Rumpf and Noell) show that from 17.5 to 40 per cent. did not go to term; in my own series 12 per cent. Space forbids discussion of the nearly related issue of sterilization.

The physical risks of abortion have been stressed repeatedly and it was ostensibly these which induced the Soviet authorities to abandon legal abortion in 1936 (H. Schneider, F. Amer. med. Ass. editorial). It has since been reintroduced. There is a small but appreciable mortality from all types 
of abortion, which Taussig, quoting Freudenberg, agrees is probably about 1.2 per cent.

Summing up, it may be said, first, that it is difficult to study this matter without becoming aware of the total problem of abortion, which Taussig has described, perhaps with the overemphasis of the specialist, as 'the most wasteful of known ills in its expenditure of human life and human health.' It is therefore vital that a branch of medicine where the indications are so uncertain should not make yet a further contribution to this. The problem, like prostitution, which it resembles so closely, is insoluble by legal or other measures. As to specific indications in psychiatry, there is no branch of medicine where the total situation must be weighed up so carefully in the light of a full knowledge of the patient and her situation and the effect this may have on her health. From my own experience I have been unable to confirm many of the ' indications' laid down at least in the earlier literature and the later more systematic studies often prove of little help in the individual case. I agree with the almost universally expressed view that interference in cases of endogenous affective illness does not influence its course and might, indeed, engender further self-reproach. In schizophrenia it may sometimes be desirable to terminate, but I am unable to confirm this from my own experience. The controversial atypical psychoses create the greatest difficulty here. Many of these are benign and in these pregnancy may be left to take its course. Neurotic and psychopathic disturbances raise the greatest difficulties and one must be ever watchful against the bogus case, of which one sees a good many. They are, however, usually easy to recognize. Particularly difficult is the case of the sexually immature woman, not infrequently with some degree of homosexual bias, ill adapted to marriage and its burdens, who is referred in her first pregnancy. Suitable treatment will more often than not enable these women to come to term without mishap and to become reconciled to the new situation. I have seen an outspokenly homosexual woman become progressively more feminized and bear two children whom she has cherished, although in her first pregnancy she threatened suicide or abortion. Nevertheless, there are many problems, as in the case of a woman of 34 , sexually immature and precariously adjusted to marriage and the stress of managing her children who was referred for an opinion on termination because of two previous (non-puerperal) depressive illnesses. The request was rejected and the patient, to her satisfaction, went to term without trouble. Two to three months later she again became depressed and was admitted. She left against advice and later committed suicide. In this case the combination of aversion to pregnancy, economic stress and liability to depressive phases might have made termination of the second pregnancy advisable. In fact, sterilizaz tion was considered later. It is difficult to know in a case like this, whether, if her second pregnancy: had been terminated, she might not have beer alive today.

In women of depressive temperament, and more당 particularly where anankastic character traits existo and much more so in face of outspoken illness therapeutic abortion is usually, if not always, in $\frac{0}{0}$ advisable. For the rest I have found no clear-cuts indication except that where a woman wishes to bear a child she must be allowed to do so. Her: judgment is more apt to be right than the doctor's. whatever constellation of unfavourable psychiatric factors may be present. In this, her mose fundamental biological function, we frequently. under-estimate her resistance to stress. I wouldP reiterate the one impression derived from my owno study, that abortion in the large majority of psychiatric cases has very little medical justification.

\section{BIBLIOGRAPHY}

AMSTAD, H. (1934), Gesundh. $u$ : Wohlf., 14, 289.

ANDERSON, E. W. (1957), Proc. roy. Soc. Med., 50, 323.

ANDERSON, E. W., HAMILTON, M. W., and KENNA, JoC

(1957), Psychiat. et Neurol., 133, 207.

BALMER, H. (1944), Mschr. Geburtsh. Gynak., 117, 201, 281. BINDER, H. (194I), 'Die Uneheliche Mutterschaft,' Bern. 응 BINDER, H. (1943), Schweiz. med. Wschr., 73, 489.

BINDER, H. (195I), Schweiz. Arch. Neurol. Psychiat., 67, 245.

BOYD, D. A. (1942), Amer. F. Obstet. Gymec., 43, 148.

BRILL, A. A. (1943), Med. Rec., 156, 409.

BUMKE, O. (1936), 'Lehrbuch der Geisteskrankheiten,' 4th ed. Munich.

COLE, R. H. (1927), Brit. med. F., il, 237.

DAVIS, A. (1950), Ibid., ii, 123.

EBAUGH, F. G., and HEUSER, K. D. (1947), Postgrad. med. f., 2, 325 .

EDEN, T. W. (1927), Brit. med. F., ii, 237.

EKBLAD, M. (1955), Acta. Psychiat. (Kbh.), suppl. 99.

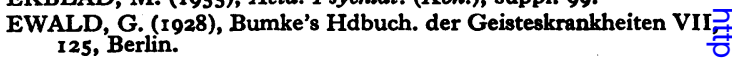

FAIRFIELD, L. (1940), Lancet, ii, 6r. FREUDENBERG, K. (1932), Münch. med. Wschr., 79, 758 (quoted
Taussig, F. J., loc. cit.).

GLAUS, A. (1948), Schweiz. med. Wschr., 78, 1947.

HART, B. (1929), Trans. Med. Soc. Lond., 52, 284.

HEFFERNAN, R. J., and LYNCH, W. A. (1953), Amer. F. Obstet Gynec., 66, 335.

HOBSON, J. A. (1953), Arch. Middx. Hosp., 3, 100.

HUMPHREYS, T. (1927), Lancet, i, 230.

JAMES, G. W. B. (1938), Ibid., ii, 217.

F. Amer. med. Ass. (1936), 107, 139 I (Editorial).

KLINTSKOG, E. (1953), Med. Leg. F. (Camb.). 21, 79.

KOGERER, E. (1931), Wien. klin. Wschr., 44, 906.

KUMMER, J. M. (1953), Calif. Med., 79, 31.

LEFERENZ, H. (1952), Nervenarzt., 23, 252.

LORD, J. R. (1927), F. ment. Sci., 73, 390.

McILROY, L. (1927), Brit. med. F., ii, 237.

MAIER, H. W. (1932), Deutsch. med. Wschr., 58, 1827.

MEINERTZ, J. (1950), Münch. med. Wschr., 92, 659.

MEYER, E. (1929), Deutsch. med. Wschr., 55, 257.

NEUWEILER, W. (1939), Mschr. Geburtsh. Gyndk., 109, 137.

NIXON, W. C. W. (1957), Proc. roy. Soc. Med., 50, 326.

PEARCE, J. D. W. (1957), Ibid., 50, 321.

PELLER, S. (1931), Wien. klin. Wschr., 44, ;17.

Bibliography continued on page 76. 
and last, division of the lateral perforating veins, of which there are usually two immediately outside the tendo Achillis.

The procedure is done sub-fascially, ${ }^{2}$ through an incision ro in. long, $\frac{3}{4}$ in. behind and parallel to the posterior border of the tibia, beginning at the internal malleolus. The bleeding is often copious; additional enlarged perforating veins may be present and are tied. My follow-up has shown that the extra-fascial operation, as initially suggested, ${ }^{2}$ is occasionally followed by recurrent symptoms.

\section{Conclusion}

Recurrent varicose veins are regrettably common, but they are curable by a full diagnosis and adequate operations (these are intellectually satisa fying, but exacting).

Venous disorders of the lower limb are a ' con tinuing' and not a 'dying' disease. Numerous citizens, who are otherwise well, are partially in: capacitated by them. These patients comprise the commonest surgical condition. Most persons? including the aged, can be returned to economie and social irculation. materially improved, if nof cured, by good treatment.

\section{REFERENCES}

I. DODD, H., and COCKETT, F. B. (1956), 'The Pathology and Surgery of the Lower Limb,' Edinburgh and London, Living:stone. 2. DODD, H., and COCKETT, F. B. (1956), Ibid., Ed nburghw
and London, Livingstone.

3. COCKETT, F. B., and JONES, D. E. (1953), Lancet, 1, 17.

\section{ANAESTHETICS \\ (Postgraduate Medical Journal)}

Price: 3s. 9d. post free

THE MODERN VIEW OF ANAESTHESIA

G. S. W. Organe, M.D., D.A., F.F.A.R.C.S.

THE PRODUCTION OF

UNCONSCIOUSNESS

B. G. B. Lucas, D.A., F.F.A.R.C.S.

ANALGESIA

J. B. Wyman, M.B.E., D.A., F.F.A.R.C.S.

MUSCLE RELAXATION IN SURGERY

Angus Smith, F.F.A.R.C.S.

CONTROL OF THE BLOOD PRESSURE

AND CONTROLLED HYPOTENSION

C. F. Scurr, M.V.O., D.A., F.F.A.R.C.S.
CHLORPROMAZINE AND ALLIED SUBSTANCES

John Beard, M.D., D.A., F.F.A.R.C.S.,

D.C.H.

CONTROLLED HYPOTHERMIA

E. J. Delorme, M.D., F.R.C.S.(C.)

MANAGEMENT OF THE APNOEIC

PATIENT

Ronald Woolmer, D.A., F.F.A.R.C.S.

THE USE OF ANTIDOTES IN.

ANAESTHESIA

B. A. Sellick, D.A., F.F.A.R.C.S.

Published by

THE FELLOWSHIP OF POSTGRADUATE MEDICINE

60, Portland Place, London, W.1

Bibliography continued from page $72-E$. W. Anderson, M.D., F.R.C.P., D.P.M.

POLONIO, P., and FIGUEIREDO, M. (1955), Mschr. Psychiat. Neurol., $130,304$.

RIDDELL, Lord (1927), Lancet, i, 219.

ROBINSON, A. L. (1933), F. Obstet. Gynaec. Brit. Emp., $40,39$.

RUMPF, E., and NOELL, W. (1950), Manch. med. Wschr., 92, 947.

SALTER, Lord Justice (1927), Lancet, i, 230.

SCHNEIDER, H. (1942), Schweiz. Arch. Neurol. Psychiat., 50, 122. SIEGFRIED, S. (I95I), Ibid., 67, 365 .

SIMSON, G. (1951), Deutsch. med. Wschr., 76, 1121.
SMITH, S. (1955), ' Forensic Medicine,' roth ed., London. STEPHENSON, H. A. (1954), Obstet. Gynec. (N.Y.), 4578. STRUB, U. M. (1943), Scheveiz. med. Wschr., 73, 493.

TAUSSIG, F. J. (1936), 'Abortion, Spontaneous and Induced, London.

TEARE, R. D. (1951), Med. Leg. F. (Camb.), 19, 81.

VALLEJO NAGERA, A. (1945), Gaz. Med. Espan., 19, 529.

WILSON, D. C. (1952), Va med. Mon., 79, 448. 